\title{
Cognitive Assessment in Middle And Elderly Aged Patients Undergoing Non-Cardiac Surgery Using Mini Mental Status Examination Score in Tertiary Care Hospital- A Prospective Observational Study.
}

\author{
Japhereena Murugavel ${ }^{1}{ }^{*}$ Swarnalingam Thangavelu ${ }^{2}$,Vasantharekha \\ Ramasamy ${ }^{3}$ \\ ${ }^{l}$ M.B.B.S,Tagore Medical College \& Hospital, \\ ${ }^{2}$ Associate Professor, Department Of Anesthesiology, Tagore Medical College \& Hospital, \\ Affiliated To TN Dr. M. G. R. Medical University, \\ ${ }^{3}$ Assistant Professor, Department Of Biotechnology, S. R. M. University, Tamil Nadu, India
}

\begin{abstract}
Background: Post operative cognitive decline is more commonly seen in elderly aged patients undergoing noncardiac surgery. The Mini Mental Status Examination (MMSE) score is routinely used as a screening test to assess the cognitive status of a patient. We aimed to assess the trend in cognitive decline among middle (4059 years) and elderly age ( $\geq 60$ years) patients undergoing elective major non-cardiac surgery.

Methods: One hundred (American Society of Anesthesiologists I,II and III) patients aged more than 40 years were followed up at regular time intervals after obtaining written informed consent. The study group patients were divided into two based on their age namely middle age (40-59years) and elderly age ( $\geq 60$ years). The cognitive testing was done at the time of pre operative assessment, $7^{\text {th }}$ day (or the time of discharge) and 3 months after surgery using MMSE score by Psychiatrist. We also collected the demographic profile along with perioperative details from the patient case sheet. Data were entered in Excel sheet and statistical analysis was done using appropriate tests.

Results: The mean MMSE score in middle age group during preoperative period and at the time of discharge were $29.86 \pm 0.35$ and $29.68 \pm 0.57$ respectively. There was no significant change in MMSE score after 3 months of surgery ( mean MMSE 29.32 \pm 0.84 ) and the change in MMSE score was only 0.54 while comparing with preoperative value. While in elderly age group patients the mean MMSE scores were 28.90 1 1.31and $28.52 \pm 1.25$ during preoperative period and at the time of discharge respectively. There was statistical difference in MMSE score 3 months after surgery between the two groups (29.32 \pm 0.84 and $28.08 \pm 1.87)$ with $p$ value of $<0.0001$

Conclusion: Even though MMSE score is routinely used for assessing the cognitive status of a patient it lacks specificity in detecting cognitive decline. To define postoperative cognitive decline clearly the study might include a battery of psychological tests.
\end{abstract}

Keywords: Postoperative cognitive decline, Mini-Mental status Examination, Major non-cardiac surgery

\section{Introduction}

Short-term changes in cognitive test performance during the first few days to weeks after surgery are well documented and typically involve multiple cognitive domains such as attention, memory and psychomotor speed. Early cognitive decline after surgery is largely reversible by three months ${ }^{1}$.Cardiac surgery is associated with less than $36 \%$ incidence of cognitive decline at six weeks post operatively ${ }^{2}$. The reported incidence of cognitive decline after major non-cardiac surgery in patients older than 65 years is $26 \%$ at one week end and $10 \%$ at three months ${ }^{3}$. Whether or not anesthesia contributes to long-term postoperative cognitive decline is controversial and an arch of intense investigation. In non cardiac procedures, anesthesia has a modest impact on long term cognitive decline, although this effect may be more robust with increasing age ${ }^{4}$. Post operative cognitive decline after major non-cardiac surgery is reversible in most cases, but may persist in approximately most of the patients ${ }^{5}$.

With this background, we conducted a prospective observational study in middle and elderly aged patients who had undergone major non-cardiac surgery. We evaluated their cognitive decline status pre and post operatively using Mini Mental Status Examination score at regular time intervals. The mental status examination is underway as soon as the physician begins observing and talking with the patient. The goal is to evaluate attention, orientation, memory, insight, judgment and group of several information. A useful screening examination of cognitive function is the Mini Mental Status Examination (MMSE), a 30 point test of cognitive 
function, with each correct answer being scored as 1 point $^{6}$. We also tried to determine the predictors of early post operative cognitive decline such as age, low educational level, pre-operative cognitive impairment, depression and surgical procedure. Patients with early post operative cognitive decline were followed up regularly to reduce the major impact on their psychosocial and mental health.

\section{Materials and methods}

After Institutional ethical committee approval, this prospective study was conducted at the department of Anesthesiology in a tertiary care hospital under the guidance of Associate Professor from April to September 2016. A written informed consent was obtained from all study participants. Since it was a prospective observational study, a sample of 100 study participants were enrolled with 50 patients in each group.

Inclusion criteria: Elective surgical patients aged between $\geq 40$ years Willing to follow up in the postoperative period

Exclusion criteria: Central nervous system disease Mini Mental State Examination (MMSE) score $\leq 23$ at the time of recruitmentHistory of drug or alcohol abuse Cardiac or neurosurgical patients Unwillingness to comply with the study protocol Inability to read and write in English language Severe visual or auditory disorders

The baseline demographic and medical data collection was done during the pre-operative assessment period from the patient record. They were divided into two groups based on age 40-59 years and > 60 years. The baseline or preoperative Mini mental status examination scoring was done by the Psychiatrist

The intra-operative details such as type of anesthesia, duration of surgery, usage of benzodiazepines along with intra-operative complications such as hypotension, hypoxic state etc were recorded from anesthesia chart. The postoperative details such as duration of ICU stay, delirium during hospital stay and re-do surgery were also taken into consideration. For this study, the participants were regularly followed up, again MMSE scoring has been done on $7^{\text {th }}$ postoperative day. At the end of 3 months following surgery, the study participants were asked to come for assessing their cognitive status. The patients with cognitive decline were followed up with Psychiatrist for rehabilitation.

\section{Results}

Descriptive statistics for continuous variable such as weight, duration of surgery were expressed as mean and standard deviation while the inferential statistics for hypothesis testing were performed with student's unpaired "t" test. Graphical representation was presented by bar diagrams. Statistical analysis was performed using Graph pad software package. Statistical significance was considered if $\mathrm{p}<0.05$. In our study, we observed both study groups were comparable to each other with respect to demographic profile (age, sex, weight, education level and ASA physical status).In middle age group, 37\% had finished their high school education and above. In elderly age group only $26 \%$ had finished their high school education. In total study population only $8 \%$ patients were belonging to ASA-physical status class 3 .

The common co-morbid conditions found in our study population were systemic hypertension $(15 \%)$ and diabetes mellitus (11\%).In elderly age group, 8 patients had previous history of surgery which was quiet comparable with middle age group. Majority of the patients underwent general surgical procedures $(43 \%)$ with remaining contribution to orthopedic (20\%), gynecological (18\%) and urological procedures(11\%).Regarding the choice /type of anesthesia, both groups were quiet comparable with other. Majority of the patients (65\%) had surgical procedures under regional anesthesia rather than general anesthesia $(35 \%)$.

In our study, we observed the statistically significant difference in the incidence of cognitive decline among the usage of volatile anesthetic agents (Sevoflurane vs Isoflurane).The duration of surgery among both groups were comparable and found to be statistically not significant.(155.44+/-45.87,148.12+/-40.76 min, $\mathrm{p}$ value of 0.4010$)$.

There was no significant incidence of perioperative adverse events in any of our patients. Among study participants, only three patients had episodes of hypotension which was manageable according to case sheets and 2 patients had experienced ICU stay for ventilator support. In our study, we found the mean MMSE Score of both study groups were $29.86 \mathrm{Vs} 28.90$ during pre-operative period, $29.68 \mathrm{Vs} 28.52$ at the end of discharge( 7 th day) and $29.32 \mathrm{Vs} 28.08$ at end of 3 months after surgery with significant $p$ value $<0.05$.The change in MMSE score from pre-operative period to the discharge time was found to be minimal (0.18 Vs 0.38 ) among both groups which was quiet comparable with scores at 3 months after surgery ( 0.54 Vs 0.82 ).

Demographic Profile

\begin{tabular}{|l|l|l|l|}
\hline Characteristics & $\begin{array}{l}\text { Middle Age Group } \\
(\mathbf{n = 5 0})\end{array}$ & $\begin{array}{l}\text { Elderly Age Group } \\
(\mathbf{n = 5 0 )}\end{array}$ & $\mathbf{p}$ value \\
\hline Age (in years) & $48.54 \pm 5.94$ & $65.40 \pm 3.00$ & $<0.0001$ \\
\hline Sex (Male/Female) & $27 / 33$ & $31 / 19$ & \\
\hline
\end{tabular}


Cognitive Assessment In Middle And Elderly Aged Patients Undergoing Non-Cardiac Surgery ...

\begin{tabular}{|c|c|c|c|}
\hline Weight & $58.72 \pm 8.89$ & $60.10 \pm 7.06$ & 0.3921 \\
\hline \multicolumn{4}{|l|}{ Education level } \\
\hline High School & $13 \%$ & $24 \%$ & \\
\hline Higher secondary & $28 \%$ & $18 \%$ & \\
\hline Graduate & $09 \%$ & $08 \%$ & \\
\hline \multicolumn{4}{|l|}{ ASA PS } \\
\hline I & $28 \%$ & $00 \%$ & \\
\hline II & $18 \%$ & $44 \%$ & \\
\hline III & $02 \%$ & $06 \%$ & \\
\hline $\begin{array}{ll}\mathrm{H} / \mathrm{O} & \text { Previous } \\
\text { Surgery } & \\
\end{array}$ & $02 / 50$ & $01 / 50$ & \\
\hline
\end{tabular}
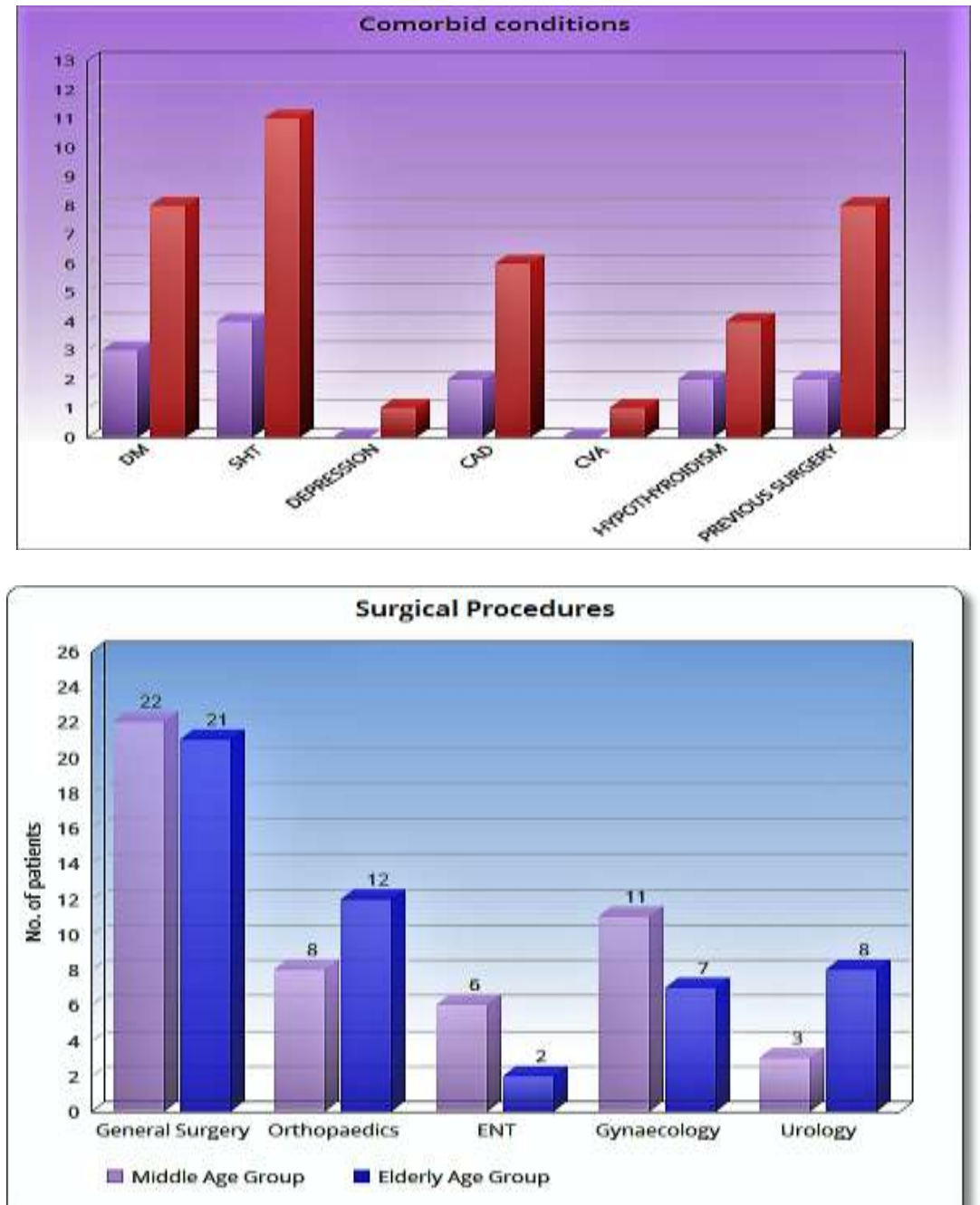

Intra-operative details

\begin{tabular}{|l|l|l|l|}
\hline Characteristics & $\begin{array}{l}\text { Middle Age Group } \\
(\mathbf{n = 5 0})\end{array}$ & $\begin{array}{l}\text { Elderly Age Group } \\
(\mathbf{n = 5 0})\end{array}$ & p value \\
\hline Type of Anesthesia & & & \\
\hline Regional & $31 \%$ & $34 \%$ & \\
\hline General & $19 \%$ & $16 \%$ & \\
\hline $\begin{array}{l}\text { Volatile Anesthetics } \\
\text { Sevoflurane }\end{array}$ & $15 / 19$ & $11 / 16$ & \\
Isoflurane & $04 / 19$ & $05 / 16$ & \\
\hline $\begin{array}{l}\text { Duration of surgery } \\
\text { in minutes) }\end{array}$ & $155.44 \pm 45.87$ & $148.12 \pm 40.76$ & 0.4010 \\
\hline Intra-op Hypotension & $01 / 50$ & & \\
\hline Hypoxia & Nil & $02 / 50$ & \\
\hline Ventilator including & $01 / 50$ & Nil & \\
ICU & & $01 / 50$ & \\
\hline Post-op delirium & Nil & $01 / 50$ & \\
\hline Re-do surgery & $01 / 50$ & $02 / 50$ & \\
\hline
\end{tabular}




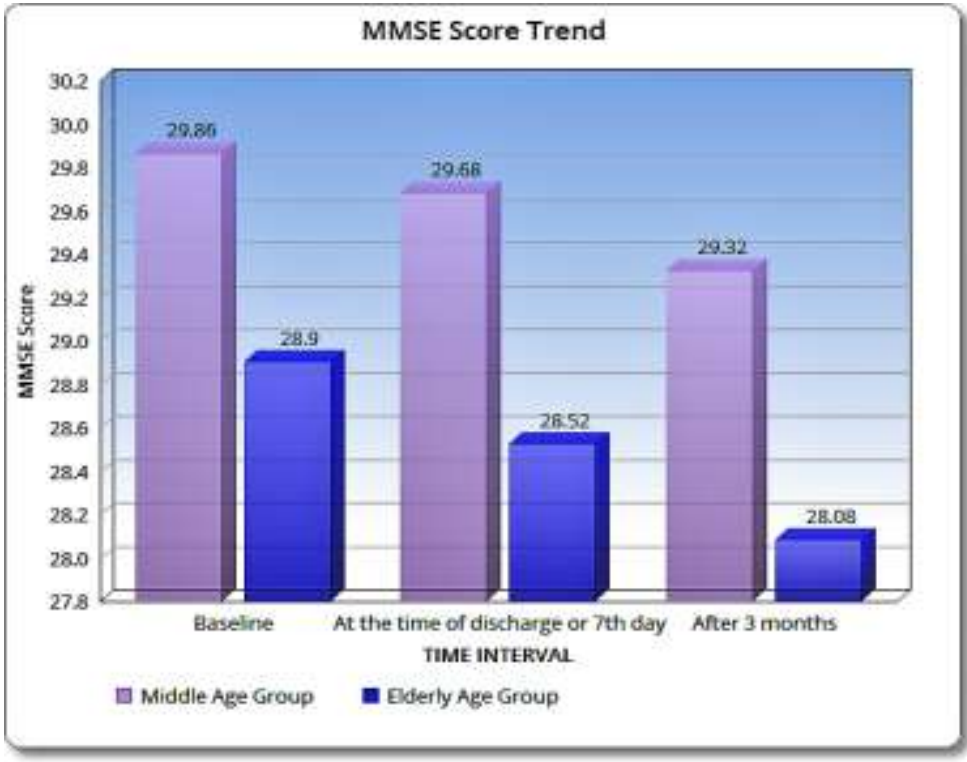

\begin{tabular}{|c|c|c|c|}
\hline Group & $\begin{array}{l}\text { Middle Age Group } \\
(\mathrm{n}=50)\end{array}$ & $\begin{array}{l}\text { Elderly Age Group } \\
(\mathbf{n}=50)\end{array}$ & p value \\
\hline $\begin{array}{l}\text { Mean/SD of MMSE } \\
\text { Preoperatively }\end{array}$ & $29.86 \pm 0.35$ & $28.90 \pm 1.31$ & $\begin{array}{l}\mathrm{t}=5.0063 \mathrm{df}=98 \\
\mathrm{p}<0.0001\end{array}$ \\
\hline $\begin{array}{l}\text { Mean/SD of MMSE Score at } \\
\text { discharge }\end{array}$ & $29.68 \pm 0.59$ & $28.52 \pm 1.25$ & $\begin{array}{l}\mathrm{t}=5.9341 \mathrm{df}=98 \\
\mathrm{p}<0.0001\end{array}$ \\
\hline $\begin{array}{l}\text { Mean/SD of MMSE Score after } \\
3 \text { months }\end{array}$ & $29.32 \pm 0.84$ & $28.08 \pm 1.87$ & $\begin{array}{l}t=4.2771 \mathrm{df}=98 \\
\mathrm{p}<0.0001\end{array}$ \\
\hline $\begin{array}{lrr}\begin{array}{l}\text { Change in } \\
\text { (Preoperative } \\
\text { discharge) }\end{array} & \text { period } & \text { to } \\
& & \\
\end{array}$ & 0.18 & 0.38 & \\
\hline $\begin{array}{ll}\text { Change in MMSE } & \text { Score } \\
\text { (Preoperative period } & \text { to } 3 \\
\text { months after surgery) } & \end{array}$ & 0.54 & 0.82 & \\
\hline
\end{tabular}

\section{Discussion}

A common problem in old age is postoperative cognitive dysfunction. Cognition is defined as the mental process of perception, memory and information processing that allow the individual to acquire knowledge, solve problems and plan for the future. It comprises the mental processes required for everyday living and should not be confused with intelligence.

Postoperative cognitive decline is strongly associated with increasing age, and as many as one in every four elderly surgical patients may be affected. It is not related to perioperative hypotension or hypoxia and typically resolve by three months after surgery. It is usually used as a failure to perform simple cognitive tasks or to complete mental tasks. In the absence of cognitive tasking, it may manifest as decreased activity during this period ${ }^{7,8,9}$. Patient may be helped by recognition that the problem is genuine and reassured that it is likely to be transient. POCD is more common in post cardiac surgeries but major non-cardiac surgeries are also associated with post-operative cognitive complications. This study was conducted to assess the cognitive level in elderly age group of patients while comparing with middle age group patients undergoing major non-cardiac surgeries. The Mini Mental Status Examination score was used to assess the cognitive level at regular time intervals ${ }^{10 .}$

Cognitive decline is characterized by a disturbance in orientation, recall, language/prexis and attention/calculation skills. It was assessed by the MMSE questionnaire in our study. Despite the wide prevalence of memory related neurological disorders amongst the aging population worldwide, the incidence of similar diseases in India are poorly examined and are more often dismissed as normal age associated memory loss or cognitive decline. Therefore we have used the mini mental status examination (MMSE) tool for cognitive assessment of older men and women along with middle aged patients. We used a simplified, scored form of the cognitive mental status examination, the "Mini Mental State" (MMS) which includes eleven questions, requires only 5-10 minutes to administer and is therefore practical to use serially and routinely. It is "Mini" because it concentrates only on the cognitive aspects of mental function and excludes questions concerning mood, abnormal mental experiences and the form of thinking ${ }^{6,11}$.

Newsmans et.al observed in a systematic review on Postoperative Cognitive Dysfunction after non cardiac surgery, a significant proportion of people show POCD in the early week with the elderly being more at 
risk $^{13 .}$ This result was well correlated with our study with low MMSE score with elderly age group at the time of discharge while comparing with middle age group patients.

The studies on regional Vs general anesthesia have not found differences in the incidence of POCD. Evered .et. al. determined the association of the type of surgical procedure and anesthesia on the incidence of POCD after procedures involving high sedation, general anesthesia for non cardiac surgery ${ }^{14}$. The POCD incidence at 3 months was independent of the nature or type of procedure or anesthetic agent when comparing non-cardiac and cardiac surgery patients ${ }^{15,16}$. In our study we have taken only non cardiac surgery patients. At the end we could not find any statistical association with surgical procedure and type of anesthesia administered in both study groups. Since none of the patient in our study group scored below 23 MMSE during their follow up but there was slight decline in MMSE score from their baseline values. This was quiet comparable with other studies done by Lalitha Jeenger. et. al, Anwer. et. al POCD with type of anesthesia employed ${ }^{17}$.

Lalitha Jeenger.et.al revealed the significant cognitive impairment in patients exposed with general anesthesia postoperatively $23.33 \%$ whereas in combined spinal with epidural anesthesia only $6.66 \%$. Duration of post operative stay did not affect the neuro cognitive function postoperatively in patients undergoing hip surgery after general anesthesia and combined spinal and epidural anesthesia ${ }^{18,19}$.

Mark et.al conducted prospective longitudinal study to investigate for the prediction of cognitive dysfunction after major non cardiac surgery. They were unable to demonstrate a relation between baseline cognitive function as measured by MMSE and the development of POCD at 3 months after surgery ${ }^{20,21 .}$ The MMSE is fundamentally a screening test and it may not be sensitive enough to detect subtle degrees of neuro cognitive impairment ${ }^{22,23,24}$. These findings were comparable with our study since we did not include neuro psychometric analytic tests other than MMSE score.

\section{Limitation of our study}

Since this study was being carried out for limited period, we could not have arrived at proper conclusion. The Mini Mental Status Examination is a screening test to assess cognitive status of a patient which cannot quantify POCD. The study will be conducted in larger sample size which includes a bundle of psychometric tests to address the decline in cognitive domain in a clear manner. Meanwhile a long term follow up is needed to look for morbidity associated with patients having a decline in cognitive trend.

\section{Conclusion}

From our study we conclude that the "Mini-Mental Status Examination" score can be used as a screening test to assess the baseline cognitive states of the patient perioperatively of considerable concern. Patient who experienced postoperative cognitive decline during hospital discharge and at end of three months after surgery need to be followed up for at least one year to define POCD widely. A detailed psychometric analysis have to be carried out in assessing each domain of cognitive function in the near future.

\section{Conflicts of interest: Nil \\ Acknowledgement: None declared}

\section{References}

[1]. Johnson T, Monk T, Rasmussen LS, et. al. Postoperative Cognitive dysfunction in middle -aged patients. Anesthesiology 96:13511357,2002 .

[2]. Neuman M F, Kirchner JL, Philips-Bute B, et al. Longitudinal assessment of neurocognitive function after coronary-artery bypass surgery. N. Engl J Med 344:395-402,2001.

[3]. Moller JT, Cluitmans P, Rasmussen LS, et.al: long term postoperative cognitive dysfunction in the elderly ISPOCD study. ISPOCD Investigators International Study of Post-operative Cognitive Dysfunction. Lancet 351:857-861,1998.

[4]. Ritchie K, Polge C, de Roquefeuil G, et.al: Impact of anesthesia on the cognitive functioning of the elderly. Int Psychogeriatric 9:309-326,1997.

[5]. Abildstrom H, Rasmussen LS, Rentowl P, et.al: Cognitive dysfunction 1-2 years after non-cardiac surgery in the elderly. ISPOCD group International Study of Post-operative Cognitive Dysfunction. Acta Anesthesiology Scand 44:1246-1251,2000.

[6]. Folstein M, Folstein S.T, Hugh MC, "Mini Mental State" a practical method for grading the cognitive state of the patients for the clinician. Journal of Psychiatric Research , 1975,12:189-198.

[7]. Price CC, Garven CW, Monk TG: Neurocognitive performance in older adults with post operative cognitive dysfunction. Anesthesiology 2003;99:A50.

[8]. Rasmussen LS. Defining Postoperative cognitive dysfunction European J Anesthesiology,1998;15:761-4

[9]. Becker AY, Weeks E J. Cognitive function after anesthesia in the elderly. Best practical Res clinical Anesthesiology,2003,17:25972.

[10]. Rasmussen LS, Larson K, Hoax P, Skovgeard LT, Hanning CD, Muller J T, et.al. The assessment of post operative cognitive function. Acta Anesthesiology Scand 2001;45:275-89.

[11]. Richardson HE, Glass JN.A comparison of scoring protocols on the clock drawing test in relation to ease of use, diagnostic group, end correlations with Mini-Mental Status Examination. J American Geriatric Society 2002,50:169-173.

[12]. Tiffany L, Tsai BA, Laura P Sends, Ph. D et.al: Postoperative cognitive dysfunction advance anesthesia,2010;28(1):269-284.

[13]. Newsmans S, Stygell J, Hirani S et.al : Postoperative cognitive dysfunction after non cardiac surgery :a systematic review Anesthesiology 2007;106: 572-590. 
[14]. Evered L, Scott DA, Sibert B, et.al: Postoperative cognitive dysfunction in independent of type of surgery and anesthesia. Anesthesia Analg 2011;112:1179-1185.

[15]. Fadtke FM, Franck M, Herbig TS et.al: Incidence and risk factors for cognitive dysfunction in patients with severe systemic disease. The journal of International Medical Research 2012,40.612-620.

[16]. Anwer HM, Swelwm ST, El-sheshai A, Monstafx AA. Postoperative cognitive dysfunction in adult and elderly patients. General anesthesia Vs Subarachnoid or epidural analgesic. Middle East J Anesthesiology,2006;18:1123-38.

[17]. Lalita Jeenger, Jitendra Jeenger, Suresh chandra Dulara et.al: A comparative study of Postoperative cognitive dysfunction in elderly patients undergoing hip surgery after general anesthesia and combined spinal and epidural anesthesia. Indian Journal of Clinical Anesthesia,2016;3(3):362-367.

[18]. Wn C, Hsn W, Richman J, Raja S Postoperative cognitive dysfunction as in outcome of regional anesthesia and analgesic. Regional anesthesia and pain medicine 2004,29:257-268.

[19]. Herring CD. Postoperative cognitive dysfunction British Journal of Anesthesia 2003;as:82-7.

[20]. Sauer AM, Kelkman C, Van dijk D. Postoperative cognitive decline. Journal Anesthesia 2009;23:256-9.

[21]. Guslvo luchi Boss, Luiz Fernendo Soares, TSA, Getulio Rodrigues de et.al: Postoperative cognitive dysfunction: prevalance and associated factors. Rev Bres Anestesial 2005;55:5:517-524.

[22]. Ramaswamy Vasantharekha, Hcnnah. P. Priyanka, Thangavel Swarnalingam et.al. Interrelationship between Mini-Mental State Examination scores and biochemical parameters in patients with mild cognitive impairment and Alzheimer's disease. Geriatric Gerantology Int 2016. DOI 10/11/11/ggi 12957.

[23]. Petersen R C, Smith GE, Wering SC et.al. Mild cognitive impairment: clinical characterization end outcome. Arch Neurol 1999;56(3):303-308

[24]. Spreen O, Strauss E General intellectual ability and pre morbid intelligence, A compendium of neuropsychological test, 2nd edition. Edited by Spreen O, Strauss E. New york, Oxford university press, 1998, PP45-72. 